\title{
Cathode Ray Tube Device
}

National Cancer Institute

\section{Source}

National Cancer Institute. Cathode Ray Tube Device. NCI Thesaurus. Code C50238.

An evacuated glass tube designed to accelerate electrons onto a screen to create images. 